\title{
الحاجات النفسية مدخل للكشف المبكرعن صعوبات التعلم النمائية لمرحلة ما قبل المدرسة
}

\author{
نواف ملعب الظفيري \\ أستاذ التربية الخاصة- كلية التربية الأساسية \\ nwaf070@hotmail.com
}

هدفت الدراسة التعرف على الحاجات النفسية (الكفاءة، الاستقلالية، الانتماء) وقدرتها على التنبؤ بصعوبات التعلم النمائية عند أطفال

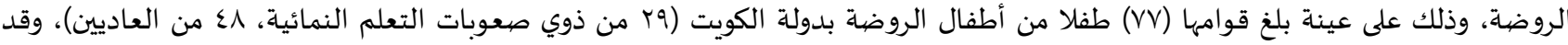

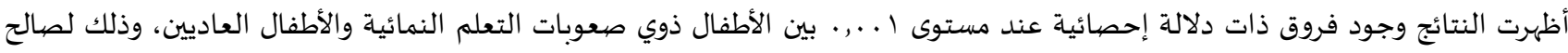
الأطفال العاديين في الحاجات النفسية، كما أظهرت النتائج وجود علاقة ارتباطية طردية دالة إحصائية بين الحاجات النفسية وصعوبات التعلم

الكلمات المفتاحية: صعوبات التعلم النمائية، الحاجات النفسية، رياض الأطفال (C) (1)

المقدمة:

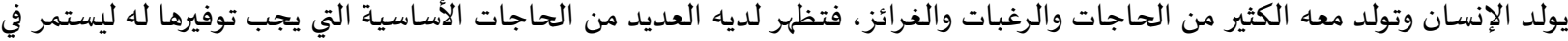

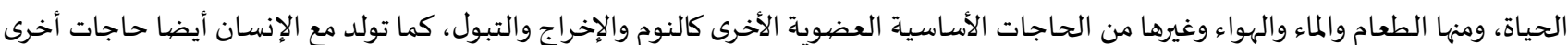

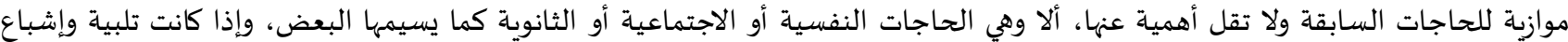

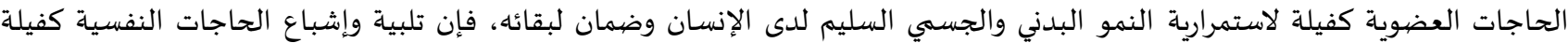

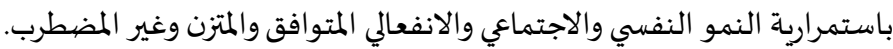

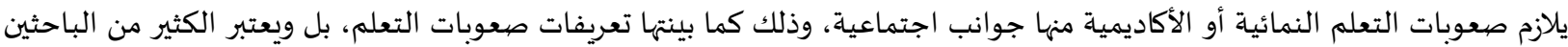

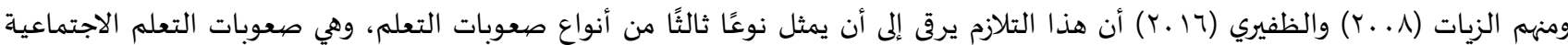
والانفعالية، وذلك بسبب الارتباط العالي والعلاقة المرتفعة بين صعوبات التعلم النمائية وصعوبات التعلم الأكاديمية والجوانب الاجتماعية والانفعالية، لذلك نجد الكثير من الدراسات في مجال صعوبات التعلم تركز على التعرف على أوجه القصور في هذه الجوانب ومحاولة علاجها التها عند هذه الفئة

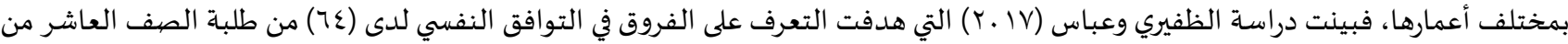

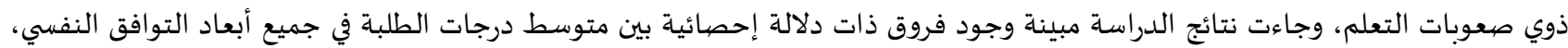

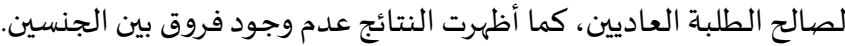

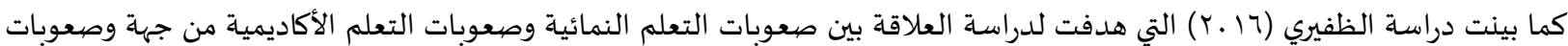
التعلم الاجتماعية والانفعالية من جهة أخرى، وذلك لدى (T) من طلبة المرحلة المتوسطة بدولة الكويت من ذوي صعوبات التعلم، وقد أظهرت النتائج

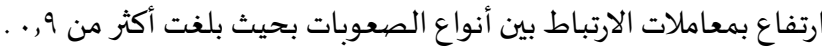

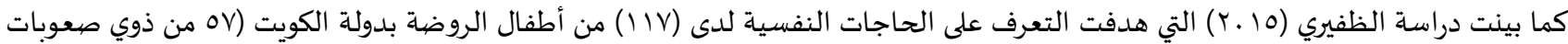

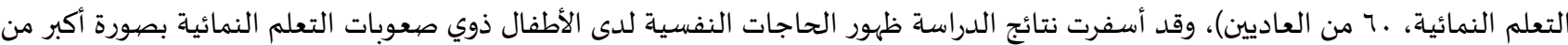
الأطفال العاديين.

كذلك بينت دراسة الظفيري (ع| ـ r) والتي كان هدفها معرفة مدى فاعلية برنامج إرشادي في تحسين المهارات الاجتماعية لدى (1) طالبًا من ذوي

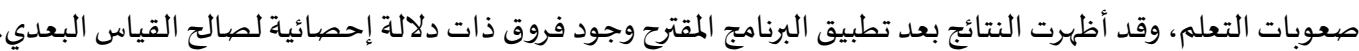

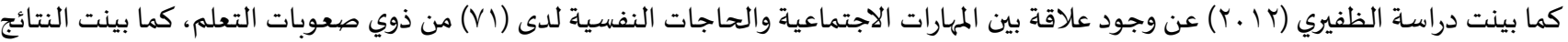
ظهور اللحاجات النفسية عند ذوي صعوبات التعلم أكثر من العاديين. 
كذلك بينت دراسة الظفيري وآخرين (r ا ـ التي هدفت التعرف على فاعلية برنامج إرشادي نفسي ديني على تحقيق الأمن النفسي لدى (9) من

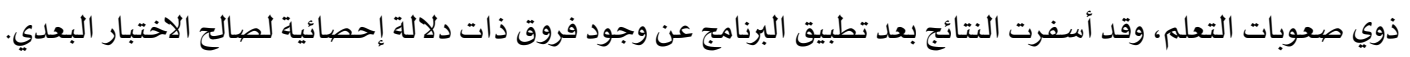

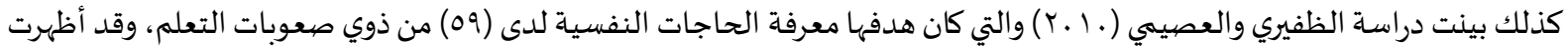

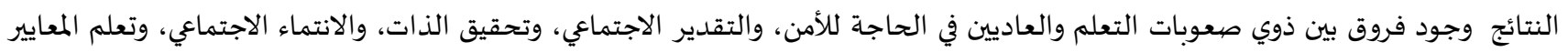

كما بينت دراسة العجمي وآخرين (Alajmi, et. al, 2010) والتي هدفت إلى قياس فاعلية برنامج تدريبي في تنمية التوافق النفسي لدى (ع إن) من

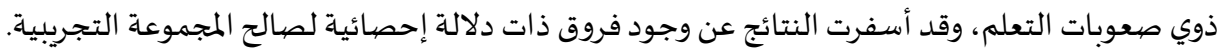

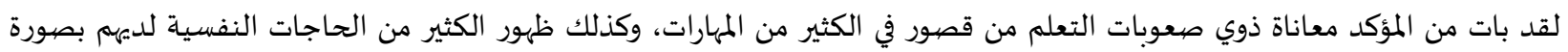

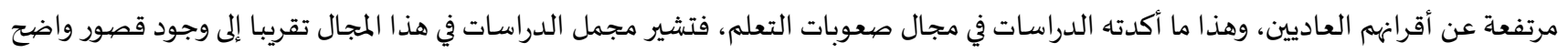

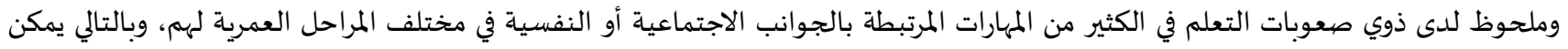
الاستفادة من ذلك في الكشف المبكر عن صعوبات التعلم من خلال التعرف على هذا الجانب في مرحلة رياض الأطفال كمؤشر عن صعوبات التعلم في

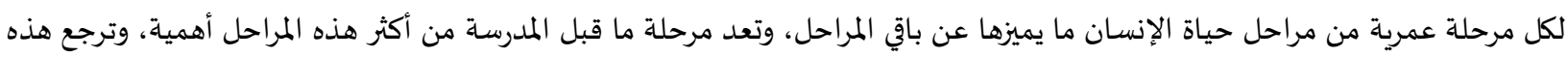

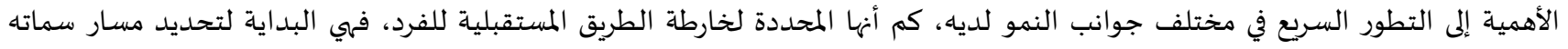

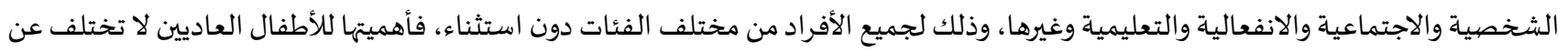

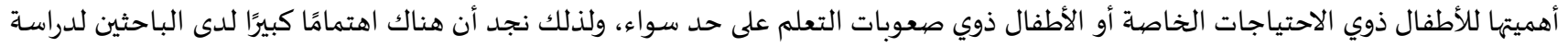

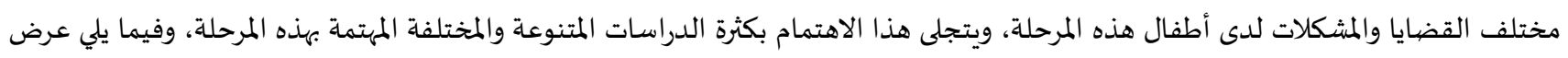

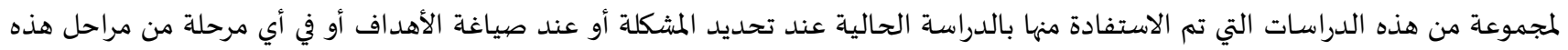
الدراسة:

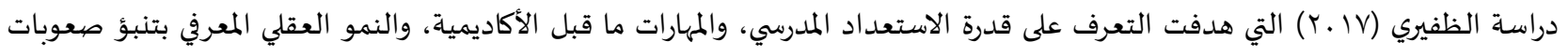

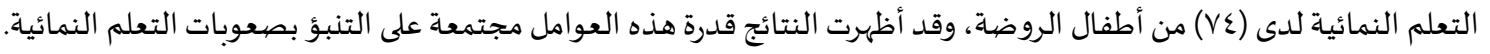

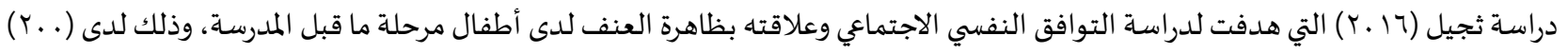

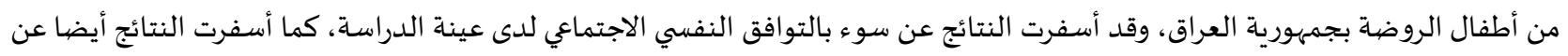

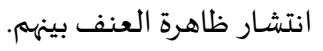

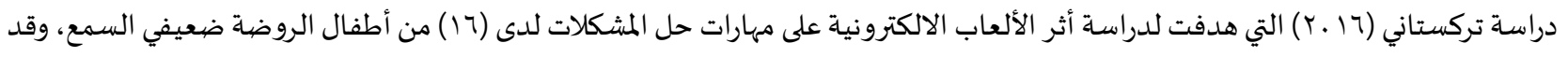

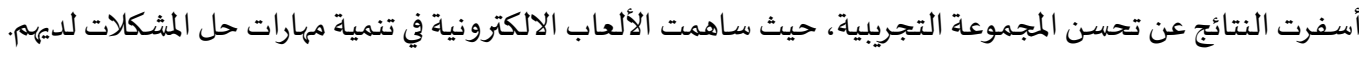

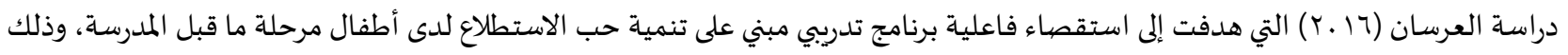

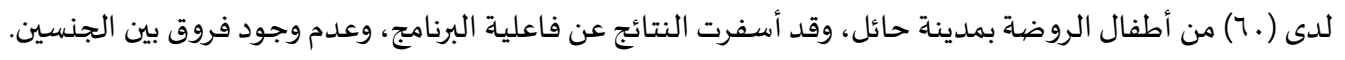

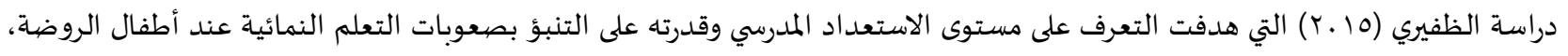
وقد أظهرت النتائج وجود فروق ذات دلالة إحصائية لصالح الأطفال العاديين في الاستعداد المالمدرسي.

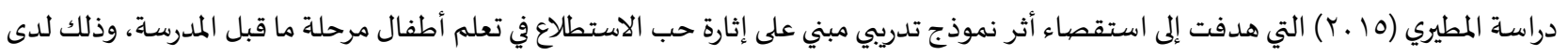

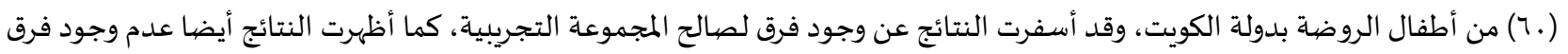

بين الجنسين.

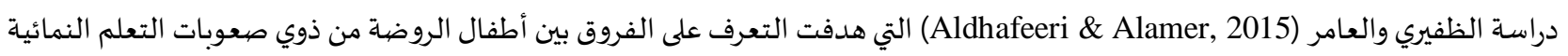

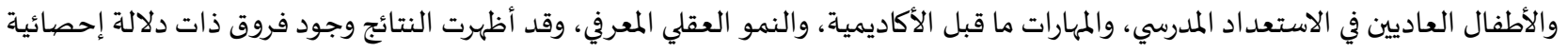

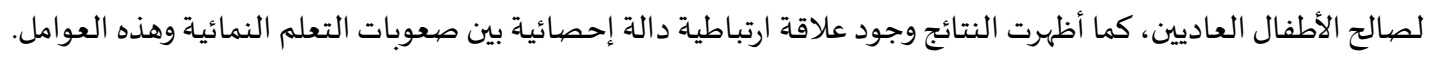

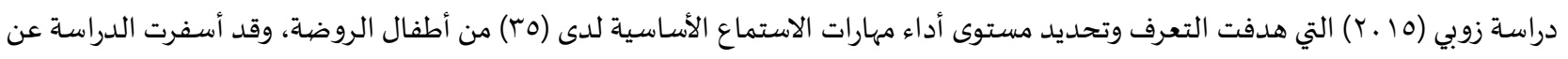

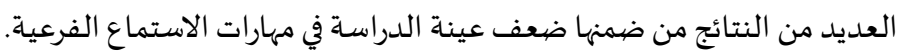

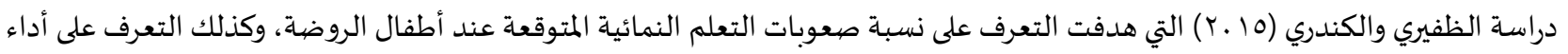

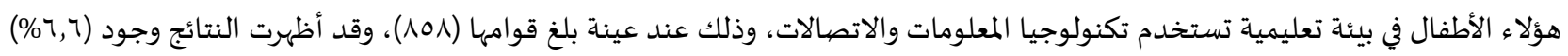


من أطفال الروضية يعانون من صعوبات تعلم نمائية، كذلك بينت النتائج قدرة مجتمع المعرفة على الكشف عن حالات صعوبات التعلم النمائية

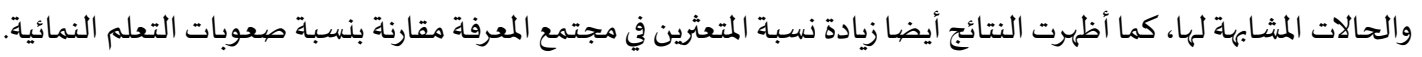
دراسـة بدر الدين (10 • ب) التي هدفت التعرف على العلاقة بين أسلوب المعاملة الوالدية المتبع في الأسرة والاكتشاف المبكر لصعوبات التعلم في مرحلة الطفولة المبكرة، وقد كشفت النتائج عن وجود علاقة بينها. دراسـة علي وآخرين (0 إب) التي هدفت التعرف على مفهوم الذات الجسمية والنفسية والاجتماعية لدى أطفال الروضة،، وذلك على عينة بلغ

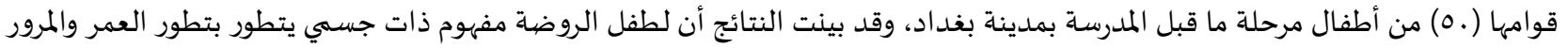
بالخبرات، ولا يوجد للأطفال مفهوم ذات نفسية أو اجتماعية. دراسـة الصانع والظفيري (ع ا ـ ب) التي هدفت التعرف على نسبة انتشار صعوبات التعلم النمائية لدى أطفال الروضية بدولة الكويت وعلاقتها بعض المتغيرات الديموغرافية (الجنس، المنطقة التعليمياة، الجنسية، عمل الأم، المستوى التعليمي للأم، المستوى التعليمي للأب، الدخل الشهري، نوع

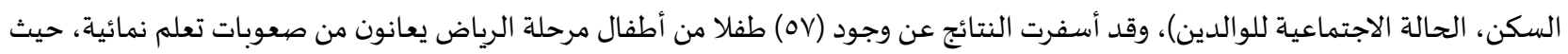

يمثلون ذسبة (7,7\%)، كما أظهرت النتائج عدم وجود اختلاف في نسب انتشار صعوبات التعلم النمائية راجع لمتغيرات الدراسة الديموغرافية. دراسة الأميري وآخرين (عا ـ ب) التي هدفت لدراسة تأخر النمو الجسمي لدى أطفال الرياض وعلاقته ببعض المتغيرات، وذلك عند (. .ع) من أطفال الروضة بمدينة بغداد، وقد أسفرت الدراسة عن العديد من النتائج من أبرزها عدم وجود علاقة تأخر النمو الجسمي والجنس وكذلك الكريك

التحصيل.

دراسـة موسى (ع ا •r) التي هدفت قياس الذاكرة قصيرة المدى لدى (.عץ) من أطفال الرياض، وقد أظهرت النتائج عن فرق بسعة الذاكرة لدى أطفال الروضية بمقدار ب وحدات عن الأطفال الأكبر سنا. دراسـة سليم والشوك (ع ا ـ r) التي هدفت لدراسـة المهارات الإبداعية في حل المشكلات البيئية لدى طفل الروضية بمدينة بغداد، وقد أظهرت النتائج ضعف في المهارات الإبداعية لدى أطفال الروضية في حل المشكلات البئئية. دراسة جرادات (rا ـr) التي هدفت لدراسة فاعلية برنامج اجتماعي لرفع مفهوم الذات للطفل الكفيف في مرحلة ما قبل المدرسة، وقد أسفرت نتائج الدراسة عن قدرة البرنامج على تحسين التكيف الاجتماعي لدى أطفال الروضية ومساهمته في ارتفاع مفهوم الذات لديهيه. دراسة المحاسنة (rا ـr) التي هدفت تقصي مشكلات رياض الأطفال في محافظة الطفيلة/ المملكة الأردنية الهاشمية من وجهة نظر المعلمات العاملات فيها، وذلك على عينة بلغ قوامها (.7) معلمة، وقد أظهرت نتائج الدراسة العديد من المشكلات ومن ضمنها عدم تضمين المناهج خططا

علاجية للأطفال ذوي صعوبات التعلم. دراسـة يباروف (Yapparova, 2013) التحليلية التي هدفت إلى التعرف على دور البيئة المختلطة في تنمية الكفاءة الاجتماعية لدى أطفال مرحلة ما قبل المدرسة بجمهورية كازخستان، حيث استدلت الدراسة بالكثير من الشـواهد على دور البيئة المدرسية المختلطة في تنمية الكفاءة الاجتماعية، كذلك لم تغفل الدراسـة عن الدور الكبير الذي تلعبه البيئة المدرسية والأسرة. دراسـة بيسنرفانبيرغ وآخرين (Peisner-Feinberg, et. al,2013) في ولاية جورجيا الأمريكية، إلى ارتفاع في التحصيل والمهارات عند أطفال مرحلة الرياض، وذلك نتيجة للبرامج المقدمة لهه، كما وجدت فرق في التحصيل يعزى لمستوى دخل الأسرة ومستواها الاقتصادي، بينما لم يوجد فرق بين المانين الجنسين في مدى اكتساب المعرفة والمهارات المختلفة.

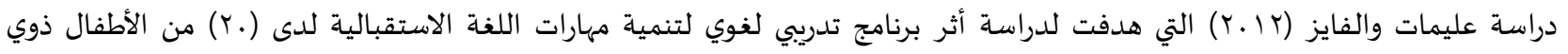

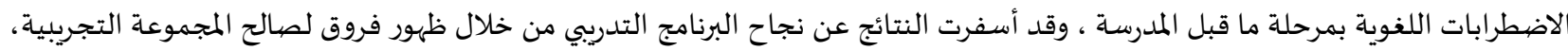
كما أسفرت النتائج عن فروق لصالح الإناث. دراسة أوموهان ولذل (Ummuhan \& Ithel, 2012) عن وجود أثر للمستوى الاجتماعي والاقتصادي للأسرة على التحصيل الرياضي لأطفال الروضية باختلاف فئاتهم العمرية. دراسـة اليتيم (Yateem, 2000) عدم تأثير متغير الجنس على التحصيل عند طفل الروضية، بينما وجدت علاقة طردية بين ارتفاع مستوى تعليم الوالدين من جهة والنمو المعرفي والاجتماعي والانفعالي للطفل.

مشكلة الدراسـة تشكل قضية الكشف المبكر لذوى صعوبات التعلم أهمية بالغة، إلى حد يمكن معها تقرير، أن فعاليات التدخل العلاجي تتضاءل إلى حد كبير

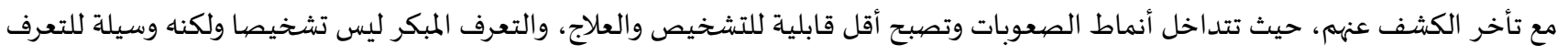


علي انحراف النمو يهدف إلى التنبؤ بالمشكلة التي من المحتمل أن تترك تأثيرا كبيرا علي نمو الطفل ومستقبله. كما تبين أدبيات مجال صعوبات التعلم

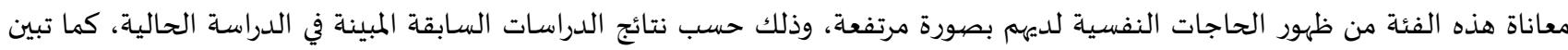

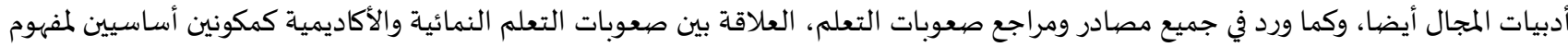

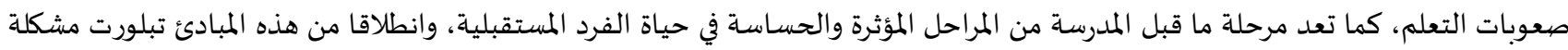

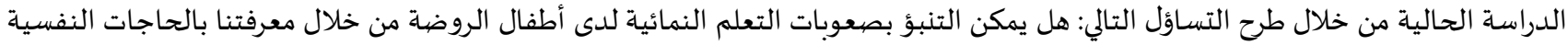

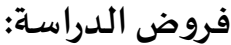

الفرض الأول: توجد فروق ذات دلالة إحصائية بين أطفال الروضة من ذواتي صعوبات الترات التعلم النمائية والعاديين في الحاجات النفسية.

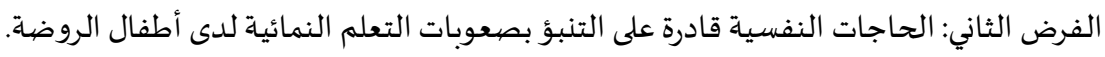

أهمية الدراسة:

تستمد الدراسة الحالية أهميتها النظرية من خلال الدور الفعال والمهم الذي تلعبه الحاجات النفسية ولا سيما الكفاءة والاستقلالية والانتماء في

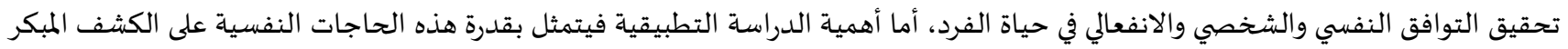

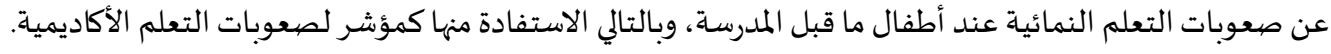

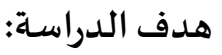

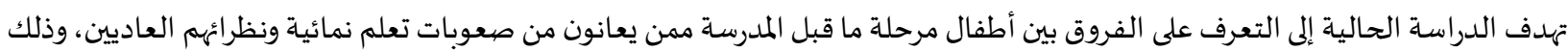
في الحاجات النفسية (الكفاءة، الاستقلالية، الانتماء)، كما تهدف الدراسة أيضا التعرف على قدرة هذه الحاجات على التنبؤ بصعوبات التعلم النمائية عند أطفال هذه المرحلة.

منهج الدراسـة: تتبع الدراسة الحالية المنهج الوصفي لمناسبته مع إجراءات هذه الدراسة، حيث تهتم الدراسة الحالية بالبحث عن الفروق بين الأطفال العاديين

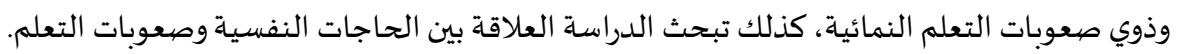

عينة الدراسة: بلغت عينة الدراسة النهائية VV طفلا من أطفال الروضة بدولة الكويت (Y من ذوي صعوبات التعلم النمائية، مع من العاديين).

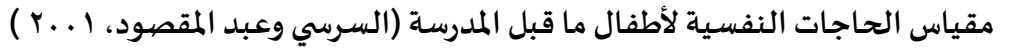

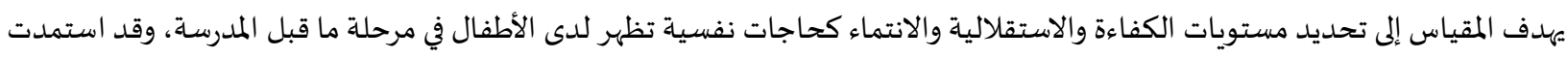

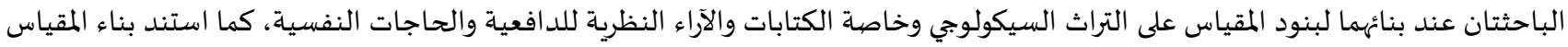

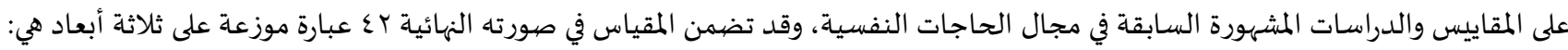

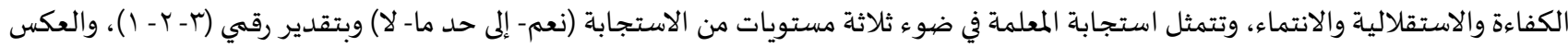

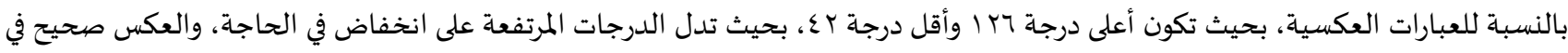
كل عبارات المقياس وأبعاده.

صدق وثبات المقياس

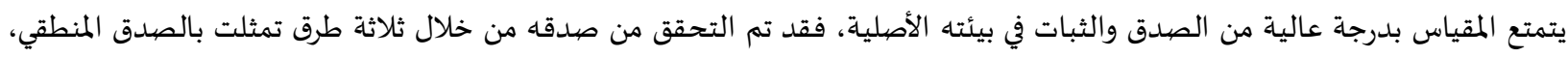

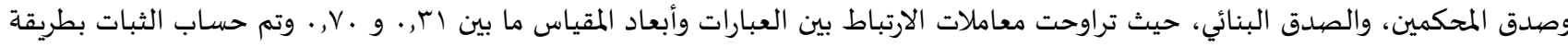

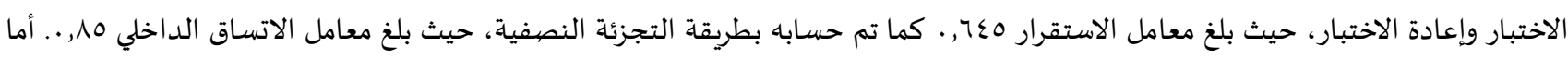

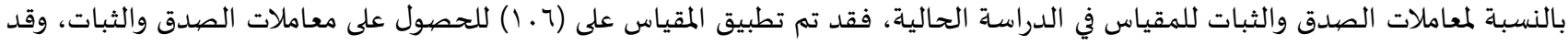


أسفرت نتائج الصيدق البنائي عن وجود معاملات ارتباط مقبولة بين مجموع درجات كل بعد بالدرجة الكلية للمقياس، ويبين جدول رقم (1) نتائج هذه المعاملات. جدول (1) (1) معاملات ارتباط الصيدق البنائي

\begin{tabular}{|c|c|}
\hline معامل الارتباط & البعد البع \\
\hline .099 & الحاجة إلى الكفاءة \\
\hline., 701 & الحاجة إلى الاستقلالية \\
\hline., $7 r \Lambda$ & الحاجة إلى الانتماء \\
\hline
\end{tabular}

يتضح من نتائج الجدول السابق لمعاملات ارتباط الصدق البنائي، وجود ارتباطات مرتفعة بين مجموع درجات كل بعد والدرجة الكلية للمقياس، حيث

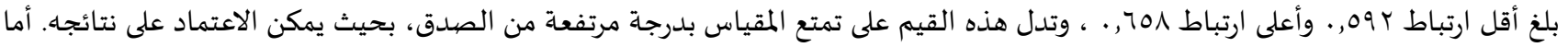

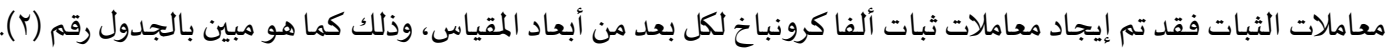
جدول (r) : معاملات ارتباط ألفا كرونباخ للثبات

\begin{tabular}{|c|c|}
\hline معامل الارتباط & الحاجة \\
\hline 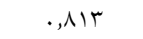 & الحاجة إلى الكفاءة \\
\hline ., V VI & الحاجة إلى الاستقلالية \\
\hline., $\mathrm{V} 09$ & الحاجة إلى الانتماء \\
\hline
\end{tabular}

يتضيح من نتائج الجدول السابق لمعاملات ثبات ألفا، وجود ارتباطات مرتفعة لكل بعد من أبعاد المقياس، حيث بلغ أقل ارتباط V09,، وأعلى ارتباط با 1 , . ، وتدل هذه القيم على تمتع المقياس بدرجة مرتفعة من الثبات، بحيث يمكن الاعتماد على نتائجها.

\section{بطارية الكشف المبكرعن صعوبات التعلم النمائية ( الفرا، 0. . ب )} تهدف البطارية الفرا إلى الكشف المبكر عن صعوبات الموبات التعلم النمائية عند أطفال الروضية، وقد حددها من خلال أربع مجالات تمثلت بصعوبات (حركية بصرية، معرفية، لغوية، اجتماعية)، تمثلها 00 عبارة تجيب عنها معلمة الروضاة في ضوء أربع مستويات من الاستجابة (دائما- غالبا- أحيانا-

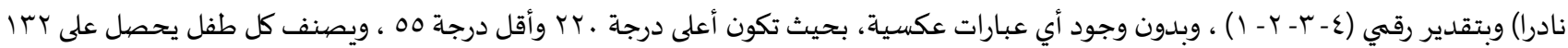

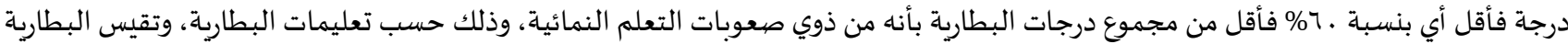

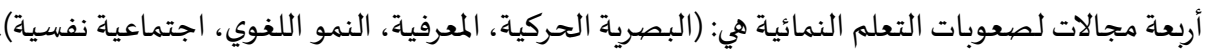
صبدق وثبات البطارية تتمتع أداة الدراسة الحالية بدرجة عالية من الصداق والثبات في بيئتها الأصلية، فقد حقق الصددق الظاهري للأداة (صدق المحكمين) نسبة اتفاق

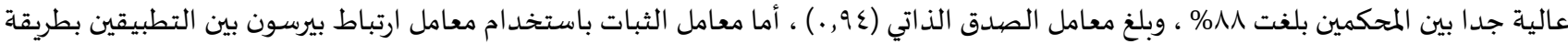

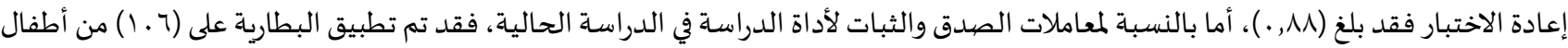

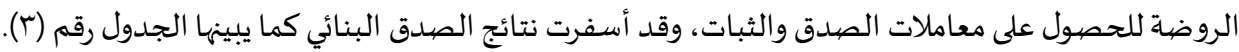

جدول (r): معاملات ارتباط الصبدق البنائي

\begin{tabular}{|c|c|}
\hline معامل الارتباط & المجال \\
\hline., $7 \uparrow \Lambda$ & الأول: صعوبات بصربة حركية \\
\hline$\cdot, \mathrm{V} \cdot \mathrm{r}$ & الثاني: صعوبات معرفية \\
\hline . $7 \times 1$ & الثالث: صعوبات النمو اللغوي \\
\hline., $\mathrm{V} \cdot \mathrm{l}$ & الرابع: صعوبات اجتماعية نفسية \\
\hline
\end{tabular}

يتضيح من نتائج الجدول السابق لمعاملات ارتباط الصددق البنائي، وجود ارتباطات مرتفعة بين مجموع درجات كل بعد والدرجة الكلية للمقياس، حيث

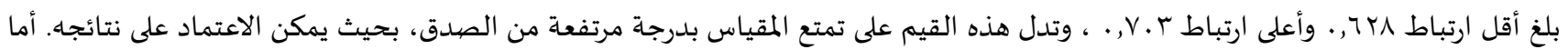

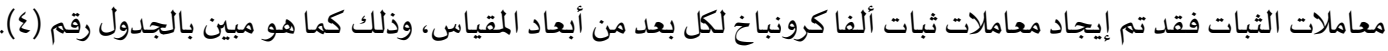




\begin{tabular}{|c|c|}
\hline معامل الارتباط & المجال \\
\hline., 109 & الأول: صعوبات بصرية حركية \\
\hline.,$\Lambda \Lambda T$ & الثاني: صعوبات معرفية \\
\hline., 771 & الثالث: صعوبات النمو اللغوي \\
\hline., 109 & الرابع: صعوبات اجتماعية نفسية \\
\hline
\end{tabular}

يتضح من نتائج الجدول السـابق لمعاملات ثبات ألفا، وجود ارتباطات مرتفعة لكل بعد من أبعاد المقياس، حيث بلغ أقل ارتباط رحار, . وأعلى ارتباط

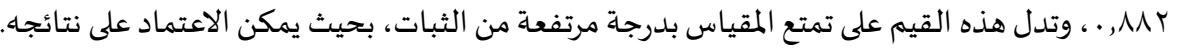

نتيجة الفرض الأول للتاكد من صحة الفرض الأول الذي نص على "توجد فروق ذات دلالة إحصائية بين أطفال الروضة من ذوي صبعوبات التحات التعلم النمائية والعاديين في الحاجات النفسية" تم الاعتماد على اختبار (ت) T-test لدرجات عينة الدراسة على مقياس الحاجات النفسية، ويبين الجدول رقم (0) نتائج هذا الاختبار.

\begin{tabular}{|c|c|c|c|c|c|c|}
\hline \multirow[t]{2}{*}{ الدلالة ل } & \multirow[t]{2}{*}{ قيمة (ت) } & \multicolumn{2}{|c|}{ صعوبات التعلم النمائية } & \multicolumn{2}{|c|}{ العاديين } & \multirow[t]{2}{*}{ الحاجة } \\
\hline & & $\varepsilon$ & 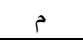 & $\varepsilon$ & م & \\
\hline.,$\ldots$ & $11,0 \leqslant r$ & $r, \cdot 1$ & $r r, q r$ & $1, r 7$ & $r \Lambda, r \mid$ & الكفاءة \\
\hline 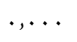 & $10, r 07$ & $1,7 \varepsilon$ & ro,ru & I,VV & $\varepsilon, 09$ & الاستقلالية \\
\hline.,$\ldots$ & $r ., .11$ & ., Vo & TV,VY & $1, \mathrm{Vq}$ & $\{V, A\}$ & الانتماء \\
\hline
\end{tabular}

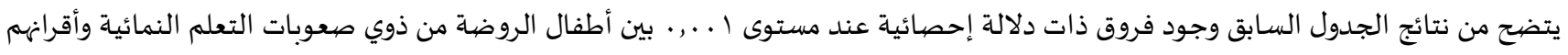

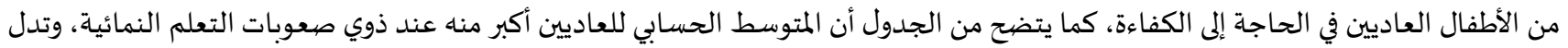

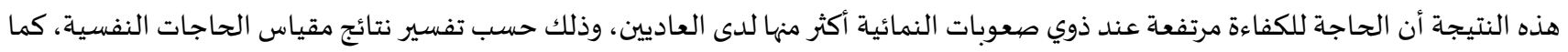

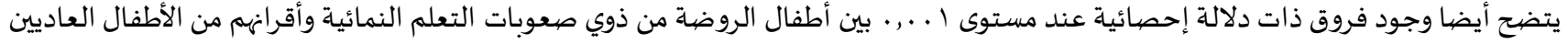

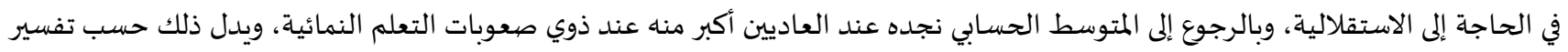

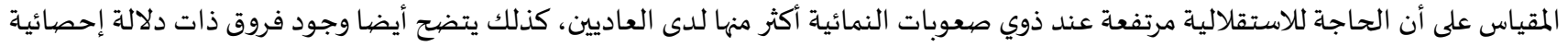

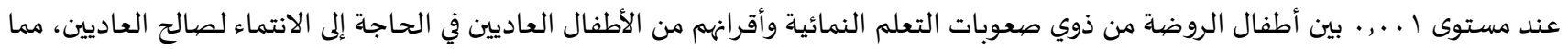
يدل على انخفاض الحاجة لديهم مقارنة بذوي صعوبات التعلم النمائية.

$$
\text { نتيجة الفرض الثاني: }
$$

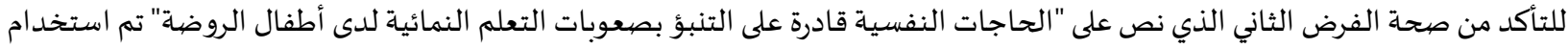

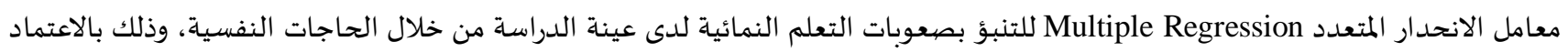

على العلاقة بينهما كما يبينها جدول رقم (7).

جدول (7): معاملات الارتباط للعلاقة بين صعوبات التعلم النمائية والحاجات النفسية

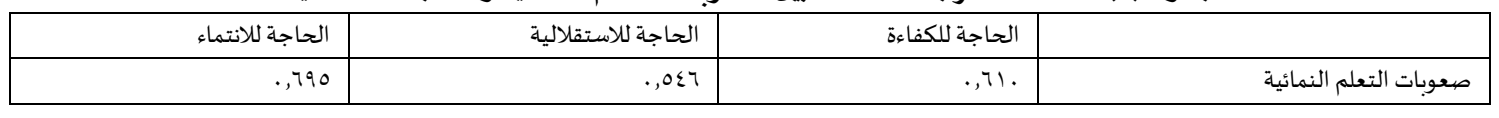

يتضح من نتائج الجدول السابق وجود ارتباطات طردية عالية بين صعوبات التعلم النمائية والحاجات النفسية لدى أطفال الروضة،، فقد بلغ معامل

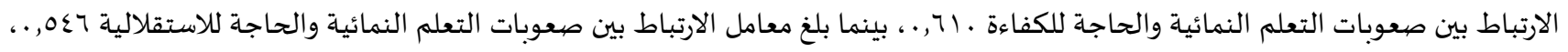

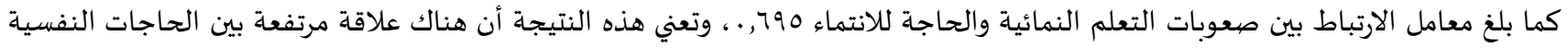

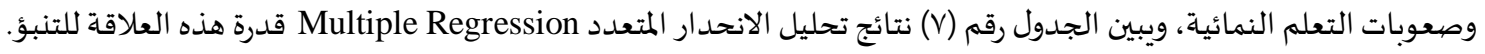


جدول (V) : تحليل الانحدار المتعدد Bultiple Regression

\begin{tabular}{|c|c|c|c|c|c|c|c|}
\hline 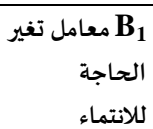 & 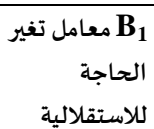 & 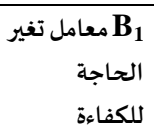 & $\begin{array}{r}\mathbf{B}_{\mathbf{0}} \\
\text { قيمة الثابت المعادلة }\end{array}$ & الدلالة & قيمة (ف) & $\mathbf{R}^{2}$ & $\begin{array}{r}\text { Rعامل الارتباط } \\
\text { R }\end{array}$ \\
\hline
\end{tabular}

يتضع من نتائج الجدول السابق وجود علاقة دالة إحصائيا عند مستوى . .,. بين الحاجات النفسية (الكفاءة، الاستقلالية، الانتماء) وصعوبات

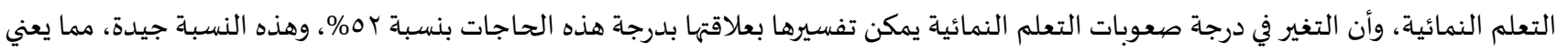
أن درجات الطفل على مقياس الحاجات النفسية قادرة على التنبؤ بدرجة الطفل على مقياس صعوبات التعلم النمائية بنسبة تصل إلى ب0\%ة.

مناقشـة النتائج:

جاءت نتائج هذا الفرض مبينة ارتفاع في الحاجات النفسية (الكفاءة، الاستقلالية، الانتماء) عند أطفال الروضية من ذوي صعوبات التعلم

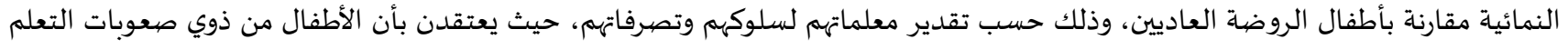

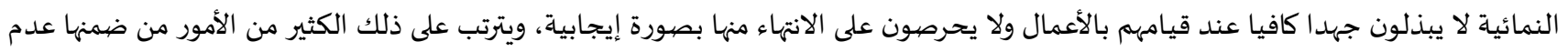
الرغبة بتعلم الأشياء الجديدة وعدم حل المشكلات والعوائق التي تواجههم، كما تظهر لديهم خشية من القيام بأعمال منفردة كالذهاب إلى الجيران،

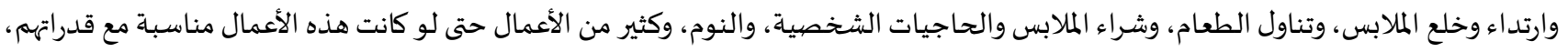

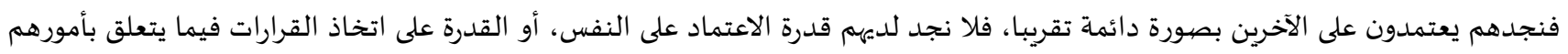

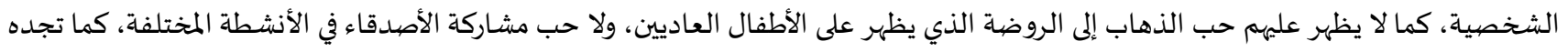

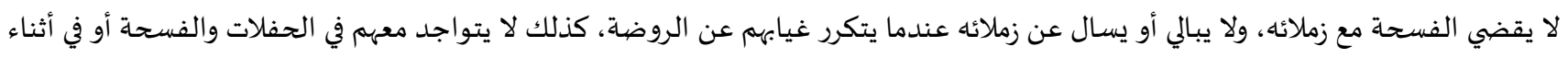

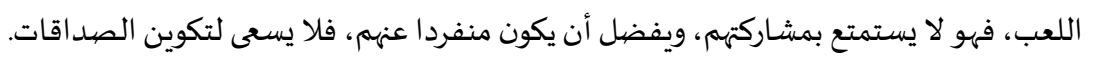

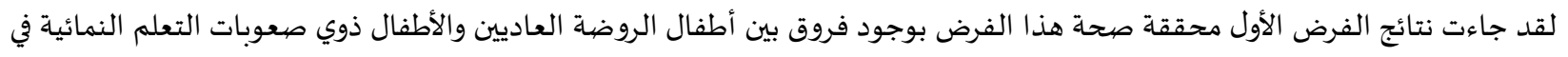

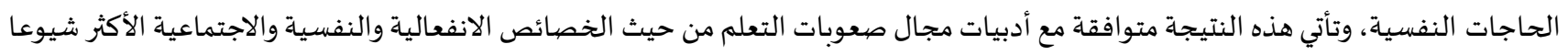

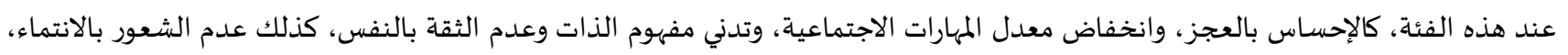

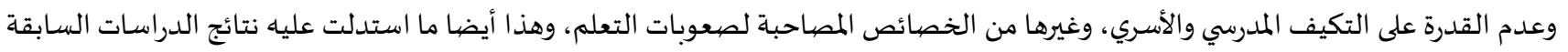
في هذا المجال التي تم استعراضها في مقدمة الدراسـة الحالية.

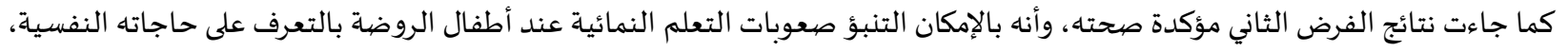

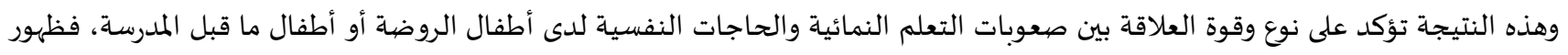

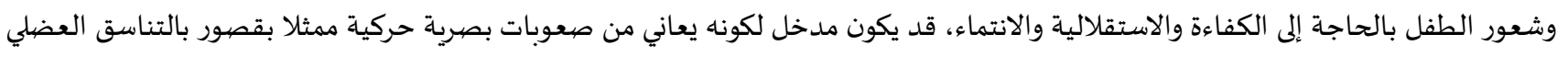

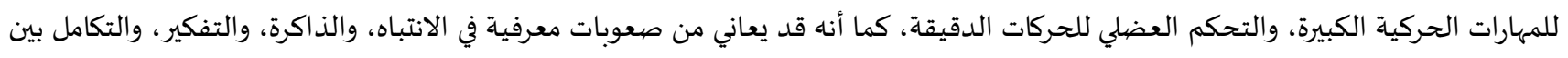

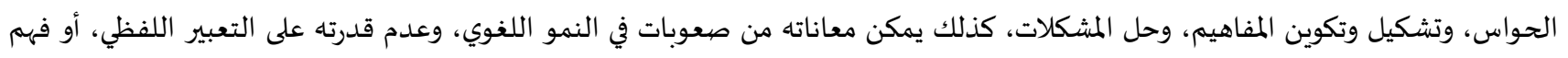

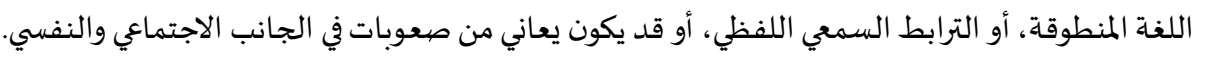

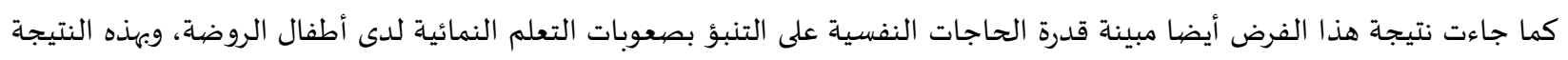
يمكن أن تضاف الحاجات النفسية إلى مجموعة كثيرة من العوامل التي يمكن أن تتنبأ بصعوبات التعلم النمائية، مثل الأداء في مجتمع المعرفية ،

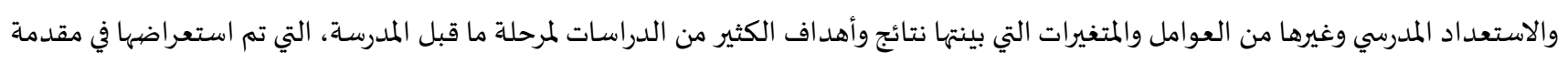
الدراسة الحالية.

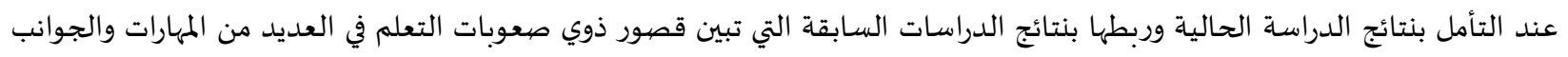

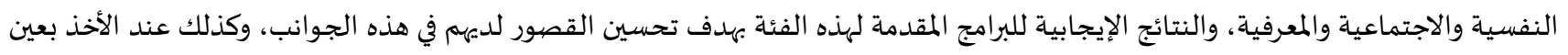

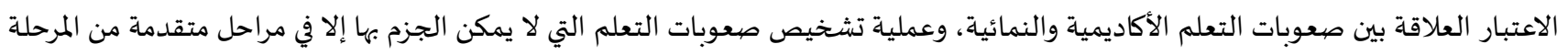

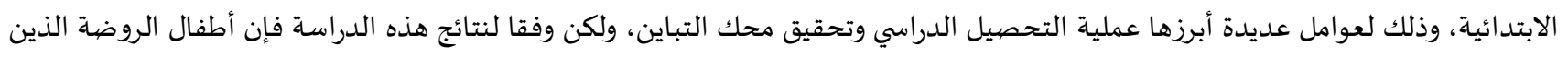

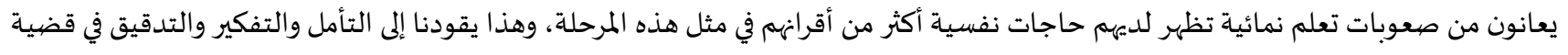

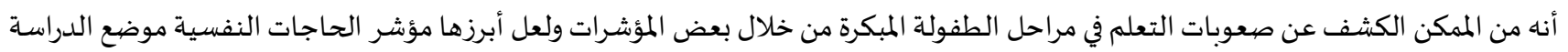

الحالية. 
بناءً على النتائج التي توصلت إلهها الدراسـة الحالية يمكن استخلاص بعض التوصيات التي يمكن أن تساعد المهتمين في هذا المجال كالتالي : الكشف المبكر عن صعوبات التعلم يساهم مساهمة فاعلة في التخفيف من حدة هذه الصعوبات وعدم تفاقمها في المستقبل.

وجود حاجة ماسة لتنويع الاختبارات والمقاييس لعملية تشخيص صعوبات التعلم النمائية لدى أطفال مرحلة ما قبل المدرسة. عملية إشباع الحاجات النفسية لدى أطفال الروضاة قد يساعد في تحسين أداء الأطفال الذين يعانون من خطر الإصابة بصعوبات التعلم. وجود معلمات رياض أطفال مؤهلات للكشف المبكر عن صعوبات التعلم النمائية.

ا. الأميري، عامر والعاني، ضحى والشمري، رغد (ع ا ـr) تأخر النمو الجسمي لدى أطفال الرياض وعلاقته ببعض المتغيرات. مجلة البحوث التربوية

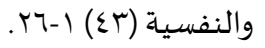

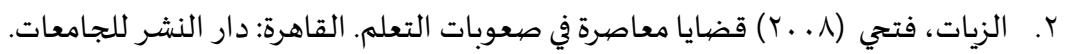

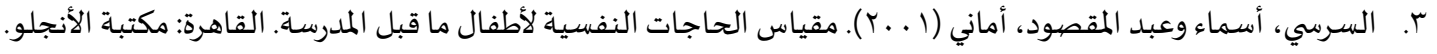

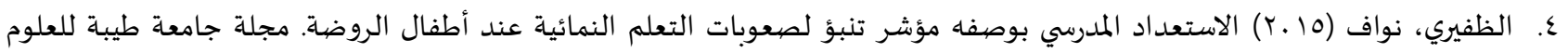

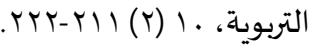
0. الظفيري، نواف ( ا ـ r ) العلاقة بين المهارات الاجتماعية والحاجات النفسية لدى طلبة الصف العاشر بدولة الكويت ( دراسة مقارنة بين الطلبة

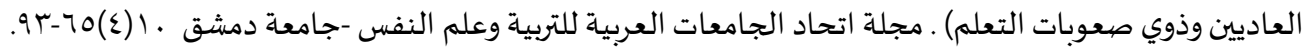

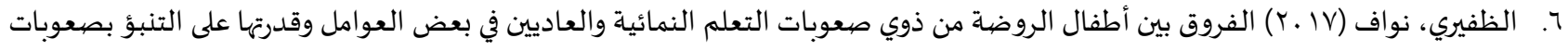

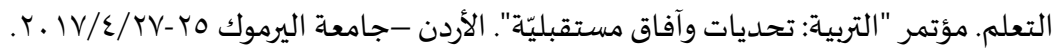

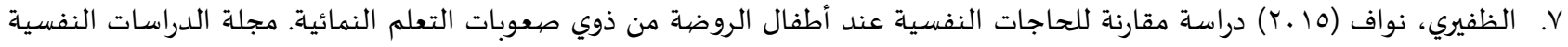

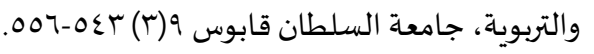
1. الظفيري، نواف (17 ـ ب) علاقة صعوبات التعلم الاجتماعية والانفعالية بصعوبات التعلم النمائية والأكاديمية. المؤتمر الدولي في التربية الخاصة

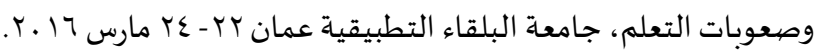
9. الظفيري، نواف (عا . ب) مدى فاعلية برنامج إرشادي في تحسين المهارات الاجتماعية لدى عينة من المراهقين ذوي صعوبات التعلم. مجلة العلوم

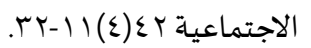
• ا. الظفيري، نواف والصانع، أحمد (عا ــr) علاقة بعض المتغيرات الديموغرافية على نسب انتشار صعوبات التعلم النمائية لدى أطفال مرحلة

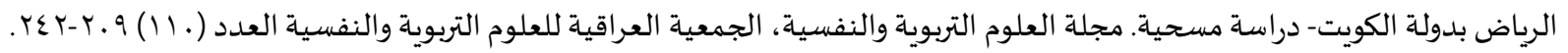

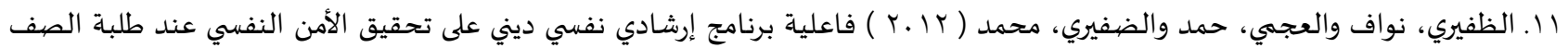

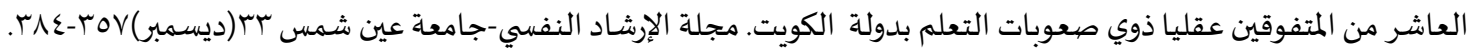

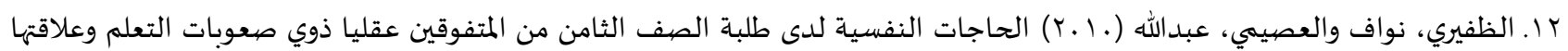

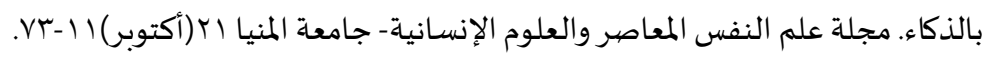

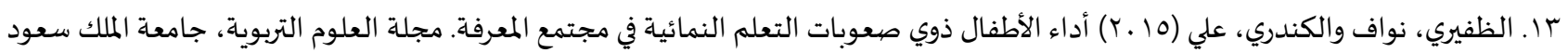
$.10-70(1) \mathrm{HV}$

ع ا. الظفيري، نواف وعباس، زينب (Vا. r) التوافق النفسي لدى الطلبة المتفوقين عقليا من ذوي صعوبات التعلم. المجلة التربوية الدولية

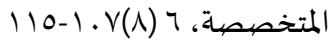

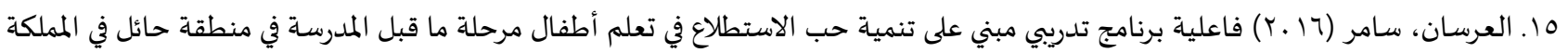

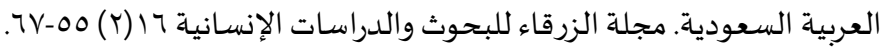

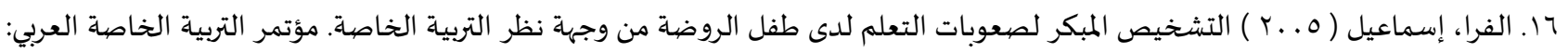
الواقع والمأمول، الجامعة الأردنية. 
V I ا المحاسنة، ربا (r ا . Y) مشكلات رياض الأطفال في محافظة الطفيلة/ المملكة الأردنية الهاشمية من وجهة نظر المعلمات العاملات فهها. مؤتة

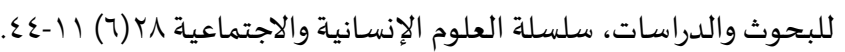

11. المطيري، سناء (10 ـ1) أثر نموذج تدريبي مبني على إثارة حب الاستطلاع في تعلم أطفال مرحلة ما قبل المدرسة بدولة الكويت. مجلة جامعة

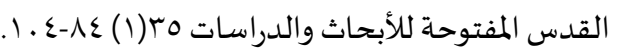

9 ا. بدر الدين، خديجة (10 ـ ب) علاقة أساليب المعاملة الوالدية بالاكتشاف المبكر لصعوبات التعلم لدى طفل ما قبل المدرسة. مجلة الدراسات

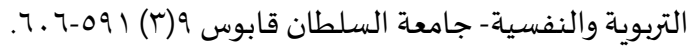
•Y. تركستاني، مريم (7 ا • Y) أثر الألعاب الإلكترونية على مهارات حل المشكلات لدى عينة من الأطفال ضعاف السمع في مرحلة ما قبل المدرسة.

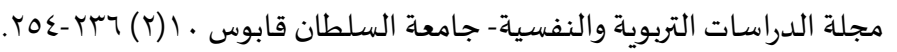

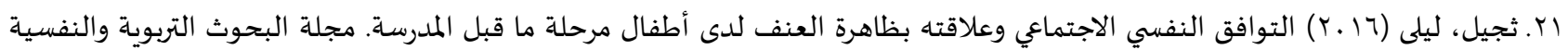
r人-l (₹q)

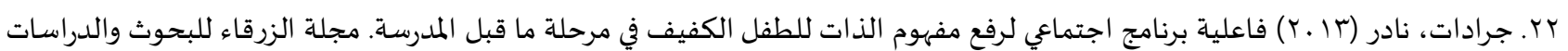
الإنسانية سبا(1)

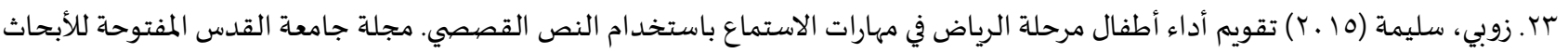
والدراسات r)

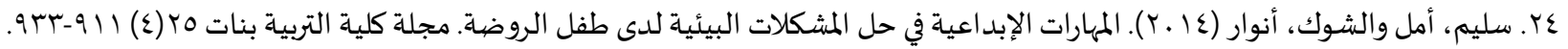

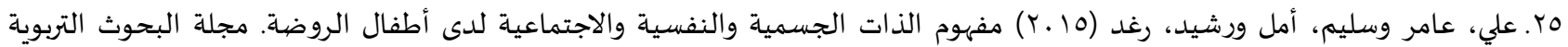

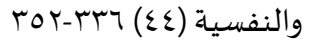

7r. عليمات، إيناس والفايز، ميرفت (Y (Y) أثر برنامج تدريبي لغوي لتنمية مهارات اللغة الاستقبالية لدى أطفال ما قبل المدرسة من ذوي

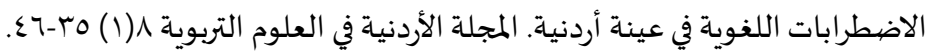

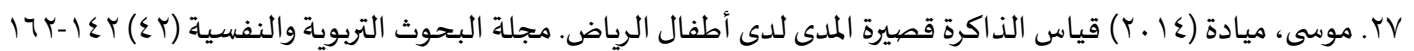

ثانياً: المراجع الاجنبية:

[1] Aldhafeeri, N \& Alamer, S., Predicting Developmental Learning Disabilities for Kindergarten Children, European Journal of Social Sciences, 49(1)(2015),105-114

[2] Al-Ajami, H. AlOsaimi\& A. AlDhafeeri, N., Effectiveness of the training program in the development of psychological adjustment among students in the sixth grade who are mentally gifted with learning difficulties, Journal of the Faculty of Education, University of Alexandria, 21(1)(2010), 375-403.

[3] Peisner- Feinberg, E. , Schaaf, J. \& LaForett, D., Children's Growth and Classroom Experiences in Georgia's Pre-K Program. UNC, Frank Porter Graham Child Development Institute, The University of North Carolina at Chapel Hill, (2013),p.1-40

[4] Ummuhan, Y. D. \& Ithel, J., The Effects of On-Time, Delayed and Early Kindergarten Enrollment on Children's Mathematics Achievement: Differences by Gender, Race, and Family Socio-economic Status, Educational Sciences: Theory\& Practice, (2012), p.3061-3074

[5] Yateem, A., The Effect of Team-Teaching upon the Kuwaiti Kindergarten Children, unpublished doctoral dissertation, Manchester University, (2000)

[6] Yapparova, G. M, Social Competence Development of the Senior Preschool Children in the Polycultural Environment, International Journal of Educational Science and Research (IJESR) 3(4)(2013),21-32 


\title{
Psychological Needs Introduction to Early Detection of Developmental Learning Disabilities for Pre-School
}

\author{
Nawaf. M. Aldhafeeri \\ Professor of Special Education - College of Basic Education \\ nwaf070@hotmail.com
}

\begin{abstract}
The aim of the study was to identify the psychological needs (competence, autonomy, and affiliation) index to predict the developmental learning disabilities with kindergarten children in Kuwait. a sample of 83 children from kindergarten children ( 29 of them with developmental learning disabilities, and 48 of normal children).

The results showed that there were significant differences $(\mathrm{P}<0.001)$ between the developmental learning disabilities and the normal children in psychological needs. Also, there were a positive correlation statistically significant between the developmental learning disabilities and psychological needs.
\end{abstract}

Keywords: Developmental learning disabilities, Psychological needs, Kindergartners

\section{References:}

[1] 'ly. 'ạmr, slym. Ạml \& rsh̆hyd. Rghnd, Mfhwm Ạldhạt Ạljsmyh Wạlnfsyh Wạlạjtmạ yh Lda Ạtṭạl Ạlrwḍh. Mjlï Ạlbḥwth Ạltrbwyh Wạlnfsyh, (44)(2015),336-352

[2] 'lymạt. AYYnạs \& ạlfạyz. Myrft, Ạ̉tḥr Brnạmj Tdryby Lgḥwy Ltnmÿ̈ Mhạaạt Ạllgḥ̈ Ạlạstqbạlyh Lda Ạ̉ṭạl Mạ́ Qbl Ạlmdrsh Mn Dḥwy Ạlạḍtrạbạt Ạllghhwyh Fy 'ynh Ạ̉rdnyh. Ạlmjlh Ạlạ̉rdnyh Fy Ạl'lwm Altrbwyh, 8(1)(2012),35-46.

[3] Al-Ajami, H. AlOsaimi\& A. AlDhafeeri, N., Effectiveness of the training program in the development of psychological adjustment among students in the sixth grade who are mentally gifted with learning difficulties, Journal of the Faculty of Education, University of Alexandria, 21(1)(2010), 375-403

[4] All'rsạn. Sạmr, Fạ lyë Brnạmj Tdryby Mbny 'ly Tnmyë Ḥb Ạlạstṭlạ' Fy T'lm Ạ̉ṭạl Mrḥlẗ Mạ Qbl Ạlmdrsh Fy Mnțqü Ḥạyl Fy Ạlmmlkh Ạl'rbyh Ậls 'wdyh. Mjlï Ạlzrqạ’ Llbḥwth Wạldrạsạt ẠlậNsạnyh, 16(2)(2016),55-67.

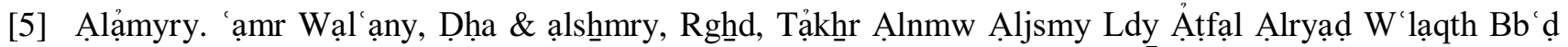
Ạlmtghyyrạt. Mjlë Ạlbḥwth Ạltrbwyh Wạlnfsyh (43)(2014) 1-26.

[6] Aldhafeeri, N \& Alamer, S., Predicting Developmental Learning Disabilities for Kindergarten Children, European Journal of Social Sciences, 49(1)(2015),105-114

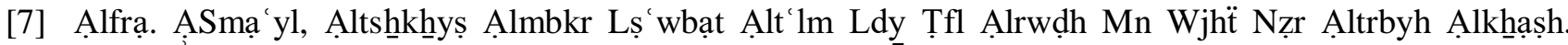
Mw̉tmr Ạltrbyh Ạlkḥạṣh Ạl'rby: Ạlwạq' Wạlmạ̉mwl, Ạljậm h Ạlạ̉rdnyh, (2005)

[8] Almhạsnh. Rbạ, Msḥklạt Ryạd Alạ̉tfạl Fy Mhạaẓ̆ Altṭylh/ Ạlmmlkh Ạlạ̉rdnyh Ạlhạshmyh Mn Wjhë Nẓr Ạlm lmạt Ạl ạmlạt Fyhạ. Mw̉th Llbḥwth Wạldrạsạt, Slslt Ạl'lwm ẠlậNsạnyh Wạlạjtmạ yh, 28(6)(2013),11-44 


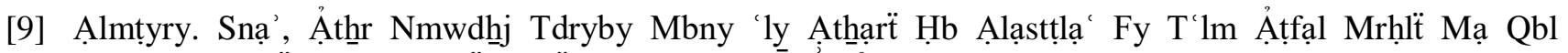
Ạlmdrsh Bdwlë Ạlkwyt. Mjlï Jạm đ̈ Ạlqds Ạlmftwh̆h Llạ̉bhạath Wạldrạsạt, 35(1)(2015), 84-104

[10] Ạlsrsy. Ạ̉smạ’ \& 'bd Ạlmqșwd. Ạ̉mạny, Mqyạs Ạlhạjạt Ạlnfsyh Lạ̉ṭạl Mạ Qbl Ạlmdrsh. Ạlqạhrh: Mktbë Ạlạ̉njlw, (2001)

[11] Alzạfyry. Nwạf \& 'bạs. Zynb, Ạltwạfq Ạlnfsy Ldy Ạlțlbh Ạlmtfwqyn 'qlyạ Mn Dhwwy Ṣ wbạt Ạlt'lm. Ạlmjlh Ạltrbwyh Ạldwlyh Ạlmtkḥș̣h, 6(8)(2017),107-115

[12] Ạlẓfyry. Nwạf \& ạl'ṣymy. 'bdạllh Ạlhạạạt Ạlnfsyh Lda Ṭlbë Ạlṣ̣ Ạltḥạmn Mn Ạlmtfwqyn 'qlyạ Dḥwy

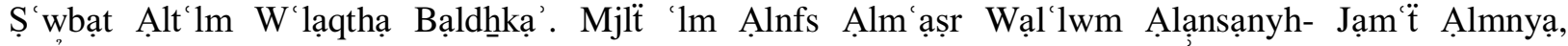
21Ạ̉ktwbr (2010)11-73.

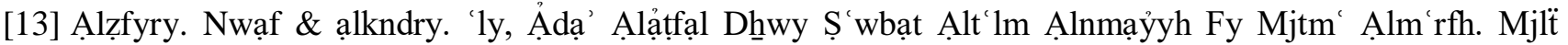
Ạl'lwm Ạltrbwyh, Jạm‘̋̈ Ạlmlk S'wd, 27(1) (2015), 65-85

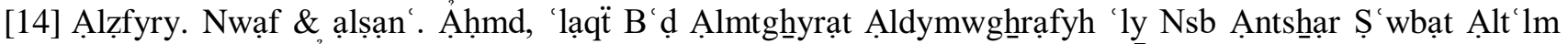
Ạlnmạyyh Lda Ạ̉ṭạl Mrḥlẗ Ạlryạ̣̣ Bdwlë Ạlkwyt- Drạsh Msḥyh. Mjlẗ Ạl'lwm Ạltrbwyh Wạlnfsyh, Ạljm yh Ạl'rạqyh Ll'lwm Ạltrbwyh Wạlnfsyh, (110)(2014), 209-242

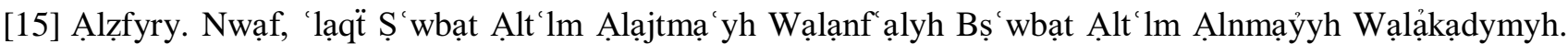

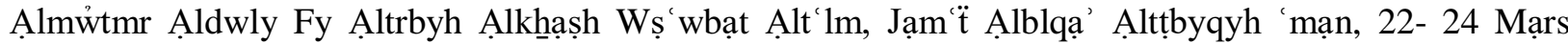
(2016)

[16] Alzfyry. Nwạf, ạl'jmy. Họmd \& ạlḍfyry, Mḥmd, Fạ lyüt Brnạmj Ạrshạdy Nfsy Dyny 'ly Tḥqyq Alạ̉mn

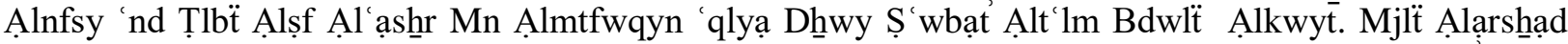
Ạlnfsy-Jạm’‘̆ 'yn Shms, 33Dysmbr (2012), 357-384

[17] Ạlzfyry. Nwạf, Ạl'lạqh Byn Ạlmhạrạt Ạlạjtmạ yh Wạlhạjật Ạlnfsyh Ldy Ṭlbł̇ Ạlṣf Ạl'ạsḥr Bdwlẗ Ạlkwyt (Drạsh Mqạrnh Byn Ạlțlbh Ạl'ạdyyn Wdhwwy Ș'wbạt Ạlt'lm). Mjil̈ Ạthạd Aljạm ạt Ạl'rbyh Lltrbyh W’lm Ạlnfs -Jạm ‘̈ Dmshq, 10(4) (2012) 65-93.

[18] Ạlzfyry. Nwạf, Ạlạst'dạd Ạlmdrsy Bwșfh Mw̉shnr Tnbw̉ Lṣ wbạt Ạlt lm Ạlnmạỷyh 'nd Ạ̉ṭậl Ạlrwḍh. Mjlï Jạm‘đ̈ Ṭybh Ll'lwm Ạltrbwyh, 10(2)(2015), 211-222.

[19] Ạlzfyry. Nwạf, Ạlfrwq Byn Ạ̉ṭạl Ạlrwḍh Mn Dhwwy Ș̣ 'wbạt Ạlt'lm Ạlnmạyyh Wạl'ạdyyn Fy B'ḍ A.l'wạml Wqdrthạ 'ly Ạltnbw̉ Bṣ’wbạt Ạlt lm. Mửtmr "Ạltrbyh: Tḥdyạt Wậfạq Mstqblỹh". Alạ̉rdn Jạm‘̋̈ Ạlyrmwk 25-27/4/2017

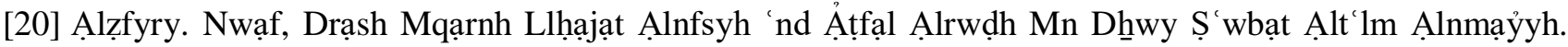
Mjlï Ạldrạsạt Ạlnfsyh Wạltrbwyh, Jạm đ̌̉ Ạlslțan Qạbws, 9(3) (2015), 543-556.

[21] Ạlẓfyry. Nwạf, Mda Fạ lyë Brnạmj ẠRshạdy Fy Tḥsyn Ạlmhạrạt Ạlạjtmạ yh Ldy 'ynẗ Mn Ạlmrạhqyn Dhwwy Ș 'wbạt Ạlt'lm. Mjlẗ Ạl'lwm Ạlạjtmạ yh, 42(4)(2014) 11-32.

[22] Ạlzyạt. Ftḥy, Qḍ̣ạạ M'ạșrh Fy Ș 'wbạt Ạlt 'lm. Ạlqạhrh: Dạr Ạlnshِr Lljạm ạt, (2008)

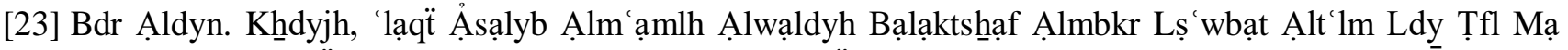
Qbl Ạlmdrsh. Mjlï Ạldrạsạt Ạltrbwyh Wạlnfsyh- Jạm ‘̈ Ạlslțạn Qạbws, 9(3)(2015), 591-606.

[24] Jrạdạt. Nạdr, Fạ lÿ̈ Brnạmj Ạjtmạ y Lrf` Mfhwm Ạldhạt Llț̣l Ạlkfyf Fy Mrḥlẗ Mạ Qbl Ạlmdrsh. Mjlï Ạlzrqạ’ Llbḥwth Wạldrạsạt ẠlậNsạnyh, 13(1)(2013),12-24

[25] Mwsa. Myạdh, Qyạs Ạldhạakrh Qṣyrẗ Ạlmda Lda Ạ̣ṭạl Ạlryạ̣̣. Mjl̈̈ Ạlbḥwth Ạltrbwyh Wạlnfsyh,(42)(2014),142-162 
[26] Peisner- Feinberg, E. , Schaaf, J. \& LaForett, D., Children's Growth and Classroom Experiences in Georgia's Pre-K Program. UNC, Frank Porter Graham Child Development Institute, The University of North Carolina at Chapel Hill, (2013),p.1-40

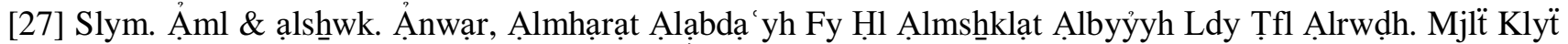
Ạltrbyh Bnạt, 25(4)(2014),911-933

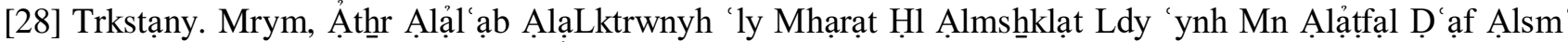
Fy Mrḥlẗ Mạ Qbl Ạlmdrsh. Mjl̈̈ Ạldrạsạt Ạltrb̄wyh Wạlnfsyh- Jạm ‘̈ Ạlsịṭan Qạbws, 10(2)(2016), 236254.

[29] Thjyl. Lyly, Ạltwạfq Ạlnfsy Ạlạjtmạ y W' lạqth Bzạhr̈̈ Ạl’nf Ldy Ạ̉ṭậl Mrḥlë Mạ Qbl Ạlmdrsh. Mjlï Ạlbḥwth Ậltrbwyh Wạlnfsyh, (49)(2016) 1-38

[30] Ummuhan, Y. D. \& Ithel, J., The Effects of On-Time, Delayed and Early Kindergarten Enrollment on Children's Mathematics Achievement: Differences by Gender, Race, and Family Socio-economic Status, Educational Sciences: Theory\& Practice, (2012), p.3061-3074

[31] Yapparova, G. M, Social Competence Development of the Senior Preschool Children in the Polycultural Environment, International Journal of Educational Science and Research (IJESR) 3(4)(2013),21-32

[32] Yateem, A., The Effect of Team-Teaching upon the Kuwaiti Kindergarten Children, unpublished doctoral dissertation, Manchester University, (2000)

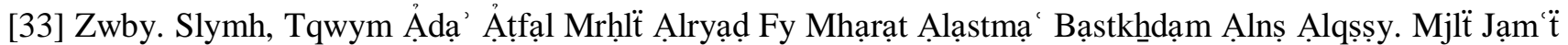
Ạlqds Ạlmftwḥh Llạ̉bhạth Wạldrạsạt, 37(2)(2015), 48-80 